\title{
Article
}

\section{Communication, stereotypes and dignity: the inadequacy of the liberal case against censorship}

\author{
Lucas, Peter
}

Available at http://clok.uclan.ac.uk/3823/

Lucas, Peter ORCID: 0000-0002-5391-3087 (2011) Communication, stereotypes and dignity: the inadequacy of the liberal case against censorship. Empedocles: European Journal for Philosophy of Communication, 2 (2). pp. 255-265. ISSN 17571952

It is advisable to refer to the publisher's version if you intend to cite from the work. http://dx.doi.org/10.1386/ejpc.2.2.255_1

For more information about UCLan's research in this area go to http://www.uclan.ac.uk/researchgroups/ and search for <name of research Group>.

For information about Research generally at UCLan please go to http://www.uclan.ac.uk/research/

All outputs in CLoK are protected by Intellectual Property Rights law, including Copyright law. Copyright, IPR and Moral Rights for the works on this site are retained by the individual authors and/or other copyright owners. Terms and conditions for use of this material are defined in the policies page.

\section{CLoK}

Central Lancashire online Knowledge www.clok.uclan.ac.uk

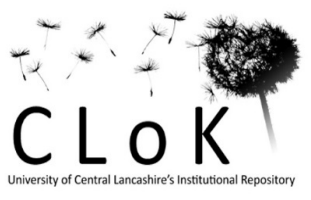


International School for Communities, Rights and Inclusion

Harrington Building

University of Central Lancashire

Preston

PR1 2HE

UK

Plucas1@uclan.ac.uk

+4401772892548

Communication, stereotypes and dignity: the inadequacy of Mill's liberal case against censorship

Peter Lucas

October 2009 
Communication, stereotypes and dignity: the inadequacy of the liberal case against censorship

Keywords: community, stereotypes, dignity, censorship

J. S. Mill's case against censorship rests on a conception of relevant communications as truth apt. If the communication is true, everyone benefits from the opportunity to exchange error for truth. If it is false, we benefit from the livelier impression truth makes when it collides with error. This classical liberal model is not however adequate for today's world. In particular, it is inadequate for dealing with the problem of stereotyping. Much contemporary communication is not truth apt. Advertising and journalism, film and fashion portray images that can be neither verified nor refuted. Moreover, where these images do bear some relation to reality, any truth they may possess is not necessarily beneficial. Cultural stereotypes, for example, can be harmful even when true, to the extent that they reflect a distorted reality (the realities of life under conditions of injustice and exploitation). Exposure to such stereotypes affects a community's selfconception. The resulting harms may be direct or indirect. Indirect harm is done when a stereotype affects a community's capacity for self-determination, perpetuating existing inequalities by restricting the options its members understand to be available to them. Direct harm is done when a stereotype induces a distorted self-conception. Pace Kant, human dignity is not purely a function of our capacity to be authors of a universal moral law. It also resides in our capacity to achieve an undistorted self-conception. Thus true communications that reflect a distorted historical reality may threaten our dignity, through their effects on our self-conception, independent of any consequences they may have for self-determining action. 
Communication, stereotypes and dignity: the inadequacy of the liberal case against censorship

Classical liberalism favours tolerance and cultural diversity. However, its efforts to foster these qualities are in tension with its refusal to countenance censorship except in cases where the relevant communications threaten to cause direct and immediate social harm. Genuine tolerance and respect for diversity, I will argue, depends on protecting the capacity of individuals and communities to form honest self-conceptions - to build, and defend, an adequate sense of their own identities. This in turn requires a more energetic approach to censorship than liberals are typically comfortable with.

For John Stuart Mill social heterogeneity is a fact of life. Human beings don't all issue from the same mould, and fostering the full development of the individual requires that we tolerate and respect the resulting diversity, rather than attempting to trim the development of the individual to fit a preconceived ideal (Mill 1962 (1859): 188). Homogeneity is in any case undesirable, since if more desirable states and forms of society are ever to be arrived at, a wide variety of "experiments in living" will be required - experiments which will need to be given every opportunity to flourish (Mill 1962 (1859): 193). It follows that, in Mill's view, liberals have good prima facie grounds for both permitting and promoting cultural diversity. Nevertheless, Mill recognises that not all experiments in living are potentially beneficial. Even tolerance must have its limits, and in limiting tolerance the principle we should abide by is the famous 'harm' principle:

$[T]$ he sole end for which mankind are warranted, individually or collectively, in interfering with the action of any of their number, is selfprotection... the only purpose for which power can be rightfully exercised over any member of a civilised community, against his will, is to prevent harm to others. (Mill 1962 (1859): 193) 
Guided by this principle, governments will sometimes be required to act to limit tolerance, to prevent harm to some segment of the population. However, where the potential harm concerns only the agent him/herself, no state intervention is either desirable or permissible. In such cases our actions and their consequences are, in Mill's view, no-one's business but our own:

[The individual's] own good, either physical or moral, is not a sufficient warrant [for government intervention]... Over himself, over his own body and mind, the individual is sovereign. (Mill 1962 (1859): 193)

It is an interesting question where communicative acts should be understood to fall here. Should they be thought of as essentially otherregarding? Or should they be thought of as essentially self-regarding (thus falling outside the scope of the harm principle)? It might seem most natural to consider communicative acts to be a species of other-regarding acts - on the basis that the attempt to communicate seems to imply an attempt to affect another, in some way. Nevertheless, Mill initially rejects this view, arguing that, for practical purposes, the vast majority of communicative acts are best considered to be self-regarding (Mill 1962 (1859): 135). He defends this approach by appeal to the idea of a distinctive freedom: the liberty of thought and discussion. The liberty to communicate freely should not, Mill argues, be thought of as an aspect of a general freedom of action. Rather, it should be thought of as an outgrowth of, and accompaniment to, the freedom to think (Mill 1962 (1859): 138). Since the liberty of expressing and publishing opinions is "practically inseparable" from the liberty of thought, it is a freedom whose exercise essentially concerns the agent him/herself, to which the usual rules concerning other-regarding actions don't apply (Mill 1962 (1859): 138).

How then does Mill deal with examples of communicative acts which promise to have significant harmful effects on others? Taking the opinion that corn-dealers are starvers of the poor as an example, he observes that such an opinion may legitimately be regarded as harmful, when delivered orally to an 
excited mob before the house of a corn-dealer (Mill 1962 (1859): 184). At the same time, he observes, the opinion would properly be regarded as innocuous if it were simply circulated through the press. What are we to conclude from this? Observing that "No one pretends that actions should be as free as opinions" (Mill 1962 (1859): 184), Mill seems to want to suggest that an address to a crowd qualifies as an action, and thus as potentially falling within the scope of the harm principle, whereas publication in a newspaper counts as simply holding an opinion (and presumably not subject to the harm principle). But this will hardly do. Both an address to a crowd and publication in a newspaper are actions. And while the extent to which each is self-regarding / other regarding will depend on the circumstances of individual cases, both are evidently other-regarding to some degree (unlike merely holding an opinion, which might plausibly be regarded as a purely self-regarding act). In the face of Mill's own example then, the attempt to distinguish systematically between opinions and actions, and to regard the expression of an opinion as purely self-regarding, fails. The expression of an opinion is an act, whether that opinion is published, or is simply expressed orally. And in the ordinary run of things any expression of opinion (as opposed to merely holding an opinion) is likely to have some detectable effect on others. The conclusion seems unavoidable then: expressions of opinion must, in principle, fall within the scope of the harm principle. The key question remains: is the relevant expression of an opinion likely to cause direct and immediate social harm? There is still scope for a liberal perspective on this, but it would have to run along something like the following lines: expressions of opinion are a species of action, and thus in principle subject to the harm principle, however: (1) when assessing the extent of the threat posed by an expression of opinion we should only consider social harms - any potential harm to the holder of the opinion is irrelevant; (2) we should, within the bounds of reasonableness, aim for maximal tolerance of divergent opinions - since the freedom to express an opinion is bound up with the (crucially important) freedom to think.

Even then though, such a revised Millian view would appear blind to the possibility that, far from enhancing our liberty, exposure to certain dangerous 
opinions might actively undermine it. This is the possibility that I will be concerned with in the remainder of this article. To introduce it, it may be helpful to begin by considering the fact that censorship may be justified by appeal to the damaging effects of certain communications on the character, rather than simply the conduct, of those who are exposed to them (Plato 1940: 337-340). The UK Obscene Publications Act 1959 for example states that:

For the purposes of this Act an article shall be deemed to be obscene if its effect... [is] such as to tend to deprave and corrupt persons who are likely... to read, see or hear the matter contained or embodied in it. (Department of Constitutional Affairs 1959: 1)

Relevant publications are to be assessed for their impact upon the character of the reader/viewer, whether or not there is any accompanying risk of significant public harm. Arguably, someone whose character has been corrupted by exposure to a pernicious opinion is less free to think and act than previously. At least, some such thought seem to lie behind the view that certain types of pornography play a significant causal role in certain types of sex-related crime exposure to such material may be held to make offenders both more likely to commit such crimes, and less free to desist from them. Of course, such a view is highly debatable. For present purposes my concern is simply that it can be argued, and should not be simply ignored. So, granting the general desirability of the liberal goal of fostering tolerance and cultural diversity, it seems important to consider whether we should agree with Mill when, in respect of communications, he exhorts us to act only in the face of clear and present social danger, and adopt a laissez faire attitude, wherever possible, to the expression of 'dangerous' private opinions. Should we only be prepared to censor material that seems likely to directly incite unlawful behaviour? Or should we also be prepared to censor communications that promise to detrimentally affect the consciousness and character of readers/viewers? (Thereby implicitly calling into question Mill's view that, in all cases, the freedom to communicate goes hand in hand with the 
freedom to think?) Prohibiting the publication of material likely to detrimentally affect our freedom to think is, in my view, sometimes the more defensible course.

To appreciate the strength of this view we will first need to consider more closely the types of harm that communications can cause. Any viable liberalism needs to acknowledge the fundamental importance of protecting human dignity. For Kant, the dignity of an individual resides in his/her capacity for rational selfdetermination (Kant 1948 (1785): 97). Acknowledging the importance of dignity, thus understood, requires us to adopt a relatively sophisticated conception of the potential harms a person might suffer. Consider the case of an individual who is benefited by an action that simultaneously undermines his/her capacity for rational self-determination - for example an actor whose performance has received numerous bad reviews, and is systematically misinformed by his manager, in order that the bad reviews do not affect his ability to perform. The actor may not be harmed, in any straightforward sense, by his manager's duplicity. He may even benefit from it (for example, financially). But his potential for rational self-determination has nevertheless been compromised by his manager's paternalistic behaviour. The potential for paternalistically undercutting another's capacity for self determination is well recognised in professional ethics, particularly in medical ethics (Campbell et al 1997: 3-4). In some cases acting in the best interests of an individual can simultaneously undermine his or her capacity to make rational, informed and self-determining choices. Consequently, it can undermine his/her dignity, in Kant's sense.

A Millian response to this question of the relationship between dignity and harm might run as follows: the fact that harms can take the form of undermining an individual's capacity for self-determination (and thus his/her dignity), rather than some more straightforward assault on his/her interests, need not lead us to reject the principle that the only purpose for which power can be rightfully exercised over any member of a civilised community, against his or her will, is to prevent harm to others. Rather, it serves to highlight the importance of rejecting a relatively narrow and unsophisticated concept of harm, in favour of a broader and more enlightened concept. And this, the response might continue, is 
precisely why the question of the liberty of thought and discussion, with which Mill opens the main body of his discussion in On Liberty, is so important (Mill 1962 (1859): 141-183). Arguably, it is only by explicitly taking into account the importance of the liberty of thought and discussion that we will be able to appreciate the value of what might otherwise appear to be harmful communications. To see the true value of the publication of dangerous opinions we need to be aware of their consequences for self-determination, rather than focussing narrowly on more straightforward notions of harm. Mill himself seems to regard protecting and fostering the liberty of thought and discussion as an essential ingredient in protecting and fostering rational self-determination, at a societal level:

The peculiar evil of silencing the expression of an opinion is, that it is robbing the human race; posterity as well as the existing generation; those who dissent from the opinion, still more than those who hold it. If the opinion is right, they are deprived of the opportunity of exchanging error for truth: if wrong, they lose, what is almost as great a benefit, the clearer perception and livelier impression of truth, produced by its collision with error. (Mill 1962 (1859): 142-3)

Of course, it should be borne in mind that the real problem that underlies concerns about paternalism resides not in the doubtful claim that the concept of harm cannot be expanded to include the undermining of dignity and selfdetermination, but in the fact that, in expanding the concept in such a way, we build a significant tension into it. In cases in which someone is materially benefited by an act that simultaneously undermines his/her capacity for selfdetermination the relevant benefits and harms are likely to look entirely incommensurable. The problem is not, then, that in such cases the very same act can benefit someone in one respect while harming them in another (such cases are familiar in e.g. medical treatment decisions, and can arguably be dealt with through some form of utilitarian calculus). The problem is that we know of 
no reliable theoretical mechanism by which more straightforward harms/benefits (pleasures, pains etc.) may be traded off against restrictions/expansions of the capacity for self-determination (Beauchamp and Childress 2001:18-23). Consequently, it is not clear how we can determine what should count as a net harm in such cases. Setting this rather large problem aside for present purposes though, let's consider instead the Millian idea that, in respect of the liberty of thought and discussion at least, the tension between beneficence and respect for self-determination tends to dissipate. Part of the importance of the liberty to air unpopular views, irrespective of their truth, lies in the fact that this is one area in which some of the more obvious tensions between benefiting others and respecting their self-determination do not arise. In promoting liberty of thought and discussion we may benefit affected parties (by maximising their opportunities to exchange error for truth), while simultaneously respecting their selfdetermination (allowing them access to the truth, and giving them the opportunity to make up their own minds). So, with the aim of assessing the liberal case on its strongest ground, let us consider the view that by adopting a liberal attitude to thought and discussion we necessarily bolster self-determination.

I want to approach the critique of this idea in a slightly roundabout way. Consider the following argument concerning the ethics of medical research. Research subjects seldom stand to benefit personally from participation in research. Consequently, there is an ever-present danger that they will find themselves reduced to the status of a means. For this reason it is important that research participants should be volunteers, who freely elect to participate. The avoidance of instrumentalisation in such cases, it is argued, hinges on the potential for close alignment between the goals of the research subject and those of the researcher (DeCastro 1988). Where there is a close alignment between the goals of both parties instrumentalisation is avoided - since participation serves the goals of the research subject, as well as of the researcher. But does such an alignment always serve to licence (along with de facto informed consent) the inclusion of participants in research? Consider these two factors: (1) Human goals are 
pretty plastic - they change over time, often quite considerably, and often as a result of volatile social factors. (2) People are suggestible when it comes to their plans and projects, and some vulnerable individuals (children, the elderly, the mentally impaired or disordered) are highly suggestible. Taken together, these factors suggest we need to be careful about any perceived alignment between the goals of researchers and those of potential research participants. In a given case we may find a genuine alignment between the goals of the research subject and those of the research. But there are many possible scenarios in which, due to the above two factors, an apparent alignment would be deceptive, and supposedly voluntary consent would not be properly voluntary at all. For example, an impressionable thirteen year-old, suffering from a bad case of moral heroism, may 'understand' the risks she is running in agreeing to participate in a study, and apparently be eager that the goals of the research should be realised, but be quite incapable of weighing those goals appropriately, in view of the risks. The fact that there is an alignment between the goals she has adopted and the goals of the research does not guarantee that her participation is voluntary in any genuine sense - her informed consent notwithstanding.

Indeed, there are circumstances in which our adoption of certain goals, far from guaranteeing that our consent is voluntary, is an index of our unfreedom.

According to some feminist theorists this is the case in supposedly consensual heterosexual sex, as well as in prostitution and the production of pornography (Dworkin, 1988). A woman may give her consent on the basis of what she believes to be her own interests. But the fact that she has consented does not guarantee that she has an accurate conception of her own interests. And in fact in any given case it might turn out that consenting is very much against her underlying interests. More generally, in any case in which the goals someone has adopted have been adopted for doubtful reasons, apparent selfdetermination may turn out to be nothing of the sort. The type of instrumentalisation that can occur in cases like this does not involve the familiar situation of one party riding roughshod over the plans and projects of the other. 
Rather, it involves the 'possession' of the consenting party - the colonisation of her identity by essentially alien goals (Dworkin 1981, 1988).

It is in light of this phenomenon of instrumentalisation-by-colonisation that the concerns we have raised regarding the liberty of thought and discussion become particularly pressing. The communications an individual or group is exposed to can have an enormous influence - for good or ill - on the goals they adopt. And protecting the liberty of thought and discussion will not necessarily serve to prevent the widespread adoption of alien goals. Thus there is no guarantee that the exercise of that liberty will not lead to the formation of various types of colonised, or otherwise false, consciousness. This phenomenon of false consciousness - of the colonisation of an individual's identity by essentially alien goals, suggests that its may be necessary for us to reconsider what might qualify as a communication "liable to deprave or corrupt". Where communications lead individuals or groups to adopt alien goals, their self-determination may be eroded, rather than enhanced.

One important vehicle by which the colonisation of individual or group identities can occur is the stereotype. Individuals or groups that adopt stereotyped selfunderstandings may have their self-determination undermined by communications that a liberal approach sees no reason to censor (since there need be nothing unlawful or immediately "dangerous" about the communications in question). We need to look more closely at stereotyping then. Potentially stereotyping communications come in more than one form. In particular, stereotypes may be truth-apt, or non-truth-apt. To begin with the non-truth-apt: The pornography, fashion and entertainment industries offer us a wide range of possible self-conceptions. We are invited to aspire to certain forms of interaction with others, to see ourselves as consumers of exciting new products, and to value highly the self that would engage in these behaviours. Even where some of the stereotypes presented have a dark side to them (involving, say, violence, crime, drug abuse and sadism), this need not reduce their attractiveness - 
perhaps because they are understood to be characteristic of more meaningful lives, if not necessarily more pleasant lives. Such communications will tend to impact differently on different groups and communities. As already mentioned, many feminist theorists have protested at the sexual stereotypes that circulate in pornography, advertising and related media (Dworkin 1981). Images of sexually attractive and 'available' women feature in communications directed at women, as well as in communications primarily directed at men - for example in fashion and related advertising, in which ideals of female attractiveness are held up not simply as intrinsically desirable, but as conferring status with respect to men. Conforming to the stereotype confers power over (some) men, while simultaneously implying subjection to others. 'Gangsta' stereotypes in music and film have a distinctive impact on black and minority ethnic communities particularly on young men living in conditions of economic and social deprivation, who are struggling to negotiate the question of what it is to deserve and receive respect, and what this may have to do with conventional notions of respectability. Such communications - part of whose implicit content is 'here is someone you could be' - proffer an ideal, a stereotype in one sense of the term. Not being truth-apt, such ideals cannot be verified or refuted. It seems evident however that the circulation of such non-truth-apt stereotypes can lead fairly directly to the adoption of inauthentic and inadequate self-conceptions. In such cases, where communications promise to significantly undermine genuine self-determination, liberal arguments for protecting the liberty of thought and discussion seem misplaced. It is impossible to mount a coherent defence of the publication of a non-truth-apt stereotype on the basis of Mill's claims concerning the importance of allowing opportunities to exchange error for truth, since non-truth-apt stereotypes offer no such opportunities. In these cases then, the goal of protecting cultural diversity and genuine self-determination might be better served by judicious censorship. This is not to suggest that all such communications are potentially harmful, or even neutral - simply that in some cases they might be, and that where they do promise to lead to the adoption of 
inauthentic and inadequate self-conceptions, Millian arguments which appeal to the importance of exchanging error for truth fail to offer us any useful guidance.

The preceding considerations cover a very wide range of relevant communications. But what of those cases - perhaps the most interesting ones in which the liberal appeal to the importance of exchanging error for truth is applicable? Is it the case that a communication that does genuinely offer us the opportunity to exchange error for truth will in all cases both benefit its recipients (or at least not harm them), and enhance their self-determination (or at least not undermine it)? I see no reason to think that a communication that is true, or largely true, should necessarily lead us to an authentic self-conception, rather than the reverse. It is a familiar fact that a true account of our own past (biographical, or autobiographical) can simultaneously be significantly distorting. The inevitable failure to tell the whole truth is one source of potential distortion. But another and deeper source lies in the inadequacy of the available conceptual resources to the task. Take even a relatively straightforward problem, such as that of accurately characterising one's social class. The concept of social class has a number of uses in social science and political theory, where it can play a genuinely explanatory role. But anyone who applies the concept to themselves and their own lives runs the risk of serious distortion. A belief about one's own class background may be, at one and the same time, both true, and stereotyping. There are several potential reasons for this:

(1) The problem of generalisation: available concepts are often not sufficiently fine-grained. In deploying concepts like social class we necessarily generalise, and generalisations can be deceptive, even where true (since they may underplay the degree of variation within a class, and/or its importance).

(2) The problem of borderline cases: the accurate application of a concept often involves an important element of judgement, which cannot necessarily be codified. 
(3) The problem of explanatory adequacy: to deploy a concept such as social class is usually to make an implicit claim about its explanatory value - and this, in any particular case, may be highly debatable. For example, there need be no inconsistency in arguing that, while the concept of social class is explanatorily valuable at the general level, it explains very little, or may even lead to a distorted picture, in particular cases. (Imagine the case of a celebrated artist, from a working class background. His biographers may have serious and legitimate disagreements concerning the extent to which it is illuminating to emphasise his background - to the point where some may reasonably claim that there is a significant distortion involved in attaching any weight to it at all.)

(4) Finally, the problem that a historical self-portrait can be 'true' without being honest, because it accurately reflects conditions of social distortion. This problem is particularly evident in respect of historical truth in cases of systematic oppression and/or injustice. True images and accounts of slavery, of concentration camps, sexual abuse, hostages, terrorism victims, subjects of police investigation etc. may all record the details of distorted lives. In such cases the historical truth may amount to a distorted portrait of the individuals or groups represented, in that it amounts to a faithful picture of distorted and distorting conditions. British school children get most of their information about the history of European Jews by learning about the holocaust. But to what extent can this lead to an accurate understanding? It may be tempting to argue that any resulting distortion is simply a consequence of the incompleteness of the picture - which could be remedied by adding more truths to the truths already taught. But isn't this over-optimistic? How far back does one need to go in recounting the history of Jews in Europe to avoid the problem that the lives one is describing were lived under conditions of prejudice and persecution, and inevitably distorted thereby? What it really means to be a European Jew is presumably something that is in many respects still to be established/discovered; and in the task of establishing/discovering it we should perhaps bear in mind Nietzsche's remark 
that it is possible to suffer from too much as well as from too little history (Nietzsche 1997 (1874)). Broadly similar observations might be made in respect of Europeans of Afro-Caribbean descent, and African-Americans. They can also be made in respect of the histories of former colonial peoples, and even in respect of the history and background of 'ordinary' working-class white Europeans. What applies here at the level of different peoples and ethnic groups also applies at the levels of genders, subgroups, and individuals. For example, what is really learned about women from the detailed memoirs of a prostitute, or any collection of such memoirs? Distortion isn't necessarily dispelled by more and better history, where what history faithfully records are the details of lives distorted by oppression, exploitation and persecution (Marcuse 1991 (1964), 123-5). A stereotype can be true, and still oppressive, then, if it originates in a context of oppression. (A point that seems to be implicitly acknowledged in antidiscrimination legislation, which requires that certain truths be put 'out of play' in job-selection processes etc.) Not only untruth undermines dignity and selfdetermination. Dignity and self-determination can also be undermined by truth. However, liberal ideas of the liberty of thought and discussion seem to fail to recognise this possibility. The opportunity to exchange error for truth is regarded by Mill as an unalloyed benefit.

\section{Conclusion}

Tolerance, and respect for diversity are important liberal values, which also have broad appeal outside of liberalism. As is recognised by all sides in the debate, protecting tolerance and cultural diversity sometimes requires societies to act to censor communications. However, as I have argued, if the potential for harm in such cases is understood in line with Mill's liberal principles, many potential threats will be overlooked. The destructive potential of a communication may involve a threat to self-determination, rather than any more conventional harm. Moreover, the potential of communications to undermine self-determination is not 
actualised exclusively through truth-apt discourse. Consequently, Mill's principles are poorly adapted to dealing with such communications. Finally, in respect of communications that are truth apt, it is a mistake to believe that exposure to them always enhances self-determination. I would argue that the above considerations suggest a need for a much richer conception of the ways in which communications may 'deprave and corrupt' individuals and communities. The area of concern is no longer the moral character of the private individual (as contrasted with the public sphere of direct legal regulation). Rather, it is the way that certain ideals and stereotypes threaten to undermine self-determination, and thus dignity, through the damage they do to our self-conceptions. In light of these concerns, it seems that the communications industry needs to develop a more informed sense of the harm communications can cause, as well as the good they can do. Communicators need to develop a sense for when judicious censorship can be the basis for fostering enlightened tolerance and diversity, rather than undermining it. There is no space here to explore the question of the most appropriate means by which this might be achieved. No doubt a full exploration of this question would involve contributing to the large and growing literature on Habermas' discourse ethics. However, in this article my much more limited aim has been that of showing that Mill's liberal proposals to defend the liberty of thought and discussion fail to afford discourse participants the protections they need. 


\section{References}

Beauchamp, Tom and James Childress (2001) Principles of Biomedical Ethics, $5^{\text {th }}$ edn. Oxford, Oxford University Press.

Campbell, Alastair et al (1997) Medical Ethics. Oxford, Oxford University Press

DeCastro, Leonardo (1998) 'Ethical Issues in Human Experimentation' in Helga Kuhse and Peter Singer (eds.) A Companion to Bioethics Oxford: Blackwell

Department of Constitutional Affairs (1959) The Obscene Publications Act 1959 http://www.opsi.gov.uk/acts/acts1959/pdf/ukpga 19590066 en.pdf

Dworkin, Andrea (1981) Pornography: Men Possessing Women London, Women's Press

Dworkin, Andrea (1988) Intercourse London, Arrow Press

Kant, Immanuel (1948 (1785)) The Moral Law: Kant's Groundwork of the Metaphysics of Morals, trans. H.J. Paton. London, Hutchinson \& Co

Marcuse, Herbert (1991 (1964)) One Dimensional Man London, Routledge

Mill, John Stuart (1962 (1859)) 'On Liberty' in M. Warnock (ed.) Utilitarianism London, Collins

Nietzsche, Friedrich (1997 (1874)) ' The Uses and Disadvantages of History for Life' in Daniel Breazeale (ed.) Untimely Meditations Cambridge, Cambridge University Press 
Plato (1940), The Republic of Plato, trans. F.M. Cornford. Oxford, Oxford University Press 